ISSN: 2238-8052

Volume 7, Número 1 (2018)

Movimentos Sociais \&

\title{
MAPAS...POR QUÊ? POR QUEM? PARA QUEM?
}

\author{
MAPAS...¿POR QUÉ? ¿POR QUIÉN? ¿PARA QUEM?
}

\author{
Marcela de Avellar MASCARELLO ${ }^{1}$ \\ Caio Floriano dos SANTOS ${ }^{2}$ \\ André Luiz de Oliveira BARBOSA ${ }^{3}$
}

Palavras-chave: Cartografia Social; Mapeamento Coletivo; Conflitos; Resistência; Territórios.

Palabras-clave: cartografía social; mapeo colectivo; conflictos; resistencia; territorios.

\section{R E S U M O}

Este artigo tem como objetivo realizar uma discussão acerca da cartografia e suas tecnologias, bem como da cartografia social e sua evolução através de uma revisão bibliográfica sobre a temática, debatendo sobre os propósitos e objetivos que envolvem a elaboração de um mapa (Por quê? Por quem? Para quem?) e as relações de poder estabelecidas. Os mapas foram historicamente construídos de forma verticalizada com o intuito de legitimar o processo de conquista por parte do Estado (posteriormente por empresas). Isso vem sendo questionado na atualidade e acaba dando lugar a novas formas de abordagem cartográficas, como por exemplo: cartografia social, mapeamentos participativos, dentre outras. A cartografia social se apresenta como um instrumento de luta que busca fortalecer os processos de resistências nos territórios contra os grandes projetos de desenvolvimento que não dialogam com as comunidades. Nesse contexto, observaram-se dois exemplos de Observatórios de Conflitos (Minas Gerais e Extremo Sul do Brasil) que têm realizado mapeamento de conflitos ambientais e assessoramento técnico à movimentos e grupos sociais em suas lutas. Foi possível concluir que os mapas são instrumentos de poder e que de forma contra-hegemônica os mapeamentos participativos possuem grande valor para empoderar as comunidades tradicionais na luta pelos seus territórios.

\section{R E S U M E N}

Este artículo tiene como objetivo realizar una discusión sobre la cartografía y sus tecnologías, así como de la cartografía social y su evolución a través de una revisión bibliográfica sobre la temática. Debatiendo sobre los propósitos y objetivos que involucran la elaboración de un mapa (¿Por qué? ¿Por quién? ¿Para quién?) y las relaciones de poder establecidas. Los mapas fueron históricamente construidos de forma vertical con la intensión de legitimar el proceso de conquista por parte del Estado (posteriormente por empresas). Eso ha sido cuestionado en la actualidad y acaban por ceder lugar a nuevas prácticas cartográficas, como por ejemplo: cartografía social, mapeos participativos, y otras. La cartografía social se presenta como un instrumento de lucha que intenta fortalecer los procesos de resistencia en los territorios contra los Grandes Proyectos de Desarrollo que no dialogan con las comunidades. En este contexto, se observan dos ejemplos de Observatorios de los Conflictos ('Minas Gerais' y 'Extremo Sul do Brasil') que han realizado mapeos de conflictos ambientales y han llevado a cabo

\footnotetext{
1 Oceanógrafa (UNIVALI), Técnica em Geoprocessamento (IFRS), Mestranda em Manejo Costero Integrado (UDELAR) e Graduanda em Direito (FURG). Pesquisadora do Observatório dos Conflitos do Extremo Sul do Brasil/ Universidade Federal do Rio Grande (FURG). E-mail: mascarellomarcela@gmail.com.

${ }^{2}$ Doutor em Educação Ambiental (PPGEA/FURG). Pesquisador do Observatório dos Conflitos do Extremo Sul do Brasil/FURG. E-mail: $\underline{\text { santoscaiof@gmail.com. }}$

${ }^{3}$ Graduando em Geografia Licenciatura na Universidade Federal do Rio Grande (FURG). Pesquisador do Observatório dos Conflitos do Extremo Sul do Brasil/FURG. E-mail: educandrebarbosa@gmail.com.
} 
el asesoramiento técnico para los movimientos y grupos sociales en lucha. Fue posible concluir que los mapas son instrumientos de poder y que de forma contra-hegemónica los mapeos participativos poseen grande valor para empoderar las comunidades tradicionales en la lucha por sus territorios.

\section{INTRODUÇÃo}

Os mapas são representações do real, a partir de uma leitura e para um determinado propósito. Os mapas políticos focam na precisão das fronteiras físicas, não dando ênfase para outros atributos importantes daquele espaço; os mapas pedológicos focam no tipo de solo, desconsiderando outros fatores, o mesmo ocorre com os geológicos que enfocam sobre a estrutura geológica da área. Portanto, todo mapa possui um contexto, um propósito, uma leitura, um discurso, e reflete as percepções e objetivos do autor (quem o demanda e quem o produz). 0 habitual é que as ferramentas de cartografia e mapas oficiais sejam elaborados; encomendados e pertençam aos mesmos grupos que possuem o poder hegemônico, ou seja, ao Estado e grandes corporações, aspirando suas intenções e os estabelecendo como verdade.

A formalização do espaço não é gratuita, nem desinteressada. Trata-se de meio de dominação indispensável criada, historicamente por oficiais e para oficiais (LACOSTE, 1988), pode-se dizer genericamente que possuem como objetivo definir o Estado como uma entidade espacial para construir nacionalismos pós-coloniais (ACSELRAD, 2008). Serve, portanto, como ferramenta de controle e domínio de povos e territórios (LACOSTE, 1988; ASSIS, 2010).

Essas informações oriundas das representações cartográficas (conhecimento sobre o espaço terrestre) passam a ser percebidas no tempo como estratégicas, no início por uma minoria dirigente (LACOSTE, 1988) e, posteriormente, por grandes corporações (nacionais, multinacionais e transnacionais). Auxiliando a definir novas possibilidades de investimentos e negócios.

Hoje, as práticas da cartografia se veem pressionadas pelas mais variadas forças envolvidas na rearticulação das disputas territoriais (ACSELRAD, 2008). Esse plano de disputas cartográficas pode ser caracterizado como uma "Guerra dos Mapas". Nomenclatura utilizada para designar um conjunto de iniciativas cujo pressuposto fundamental foi contribuir para a afirmação territorial de grupos sociais atingidos pelo Projeto Grande Carajás; e o Projeto Mamirauá para fins de manejo e preservação da biodiversidade (ACSELRAD; COLI, 2008).

Como destaca Lacoste (1988), este "amenagement" do território não possui como único objetivo a maximização do lucro mas, também a organização estratégica do espaço econômico, social e político, de forma a abafar qualquer tipo de movimento popular em contra dos interesses do Estado ou das grandes Corporações.

Neste campo de disputa, a cartografia social/mapeamentos participativos ou outras terminologias, desde que utilizadas como esforços de resistência, reunindo experiências que buscam 
fortalecer processos políticos autônomos, destinadas a deter os efeitos expansivos e expropriatórios do regime de acumulação prevalecente (ACSELRAD, 2008), tornam-se importantes instrumentos de luta que procuram representar os espaços sociais que se encontram fora do mapa (DAOU, 2013).

Se o Estado e as Empresas utilizam destes recursos para legitimar suas ações e controlar o território, dando visibilidade somente para o que lhe interessa, porque não se apropriar de tais instrumentos em um movimento contra-hegemônico para garantir o acesso à terra e a perpetuação de práticas culturais? Contando sua própria história, valorizando (afirmando) sua identidade e utilizando de tais instrumentos para legitimar suas práticas? Afinal, "na perspectiva dos chamados 'atingidos' pelos projetos de desenvolvimento, o lugar é referência para a construção de suas identidades políticas, ele significa, sobretudo, a retomada do controle de seu próprio destino." (ZHOURI; OLIVEIRA, 2010).

Neste contexto, o objetivo deste artigo é fazer uma discussão acerca da cartografia e suas tecnologias, bem como da cartografia social e sua evolução, trazendo alguns exemplos em que a cartografia social tem sido apropriada pelas comunidades e tem se consolidado como instrumento de luta.

São ainda mais importantes em situações de conflitos e injustiças ambientais, sendo definidos respectivamente como: disputas envolvendo grupos sociais com modos diferenciados de apropriação, uso e significação do território, quando um dos grupos tem a continuidade das formas de apropriação do meio ameaçadas por impactos indesejáveis - transmitidos pelo solo, água, ar ou sistemas vivos decorrente do exercício das práticas de outros grupos (ACSELRAD, 2004) e imposição desproporcional dos riscos ambientais às populações menos dotadas de recursos financeiros, políticos e informacionais (ACSELRAD et al., 2009, p. 9) o que se faz visível em projetos como: Povos e Comunidades tradicionais: Nova cartografia social e Mapa de Conflitos envolvendo Injustiça Ambiental e Saúde no Brasil.

0 artigo traz ainda um breve relato sobre dois observatórios dos conflitos do Brasil (Observatório dos Conflitos Ambientais de Minas Gerais e Observatório de Conflitos Urbanos e Socioambientais do Extremo Sul do Brasil) que vêm mapeando conflitos no sentido de servir de ferramenta de luta para estas comunidades injustiçadas ambientalmente.

\section{OS MAPAS COMO PODER HEGEMÔNICO}

Os mapas possuem papel fundamental na consolidação das sociedades atuais, bem como estão presentes na história de muitas civilizações. Como diz Lévy (2008, p. 153) "o locus da produção da cartografia é societal, na medida em que ele concerne, ao mesmo tempo, o conhecimento teórico e a vida cotidiana, a linguagem e a tecnologia, o econômico e o político". 
Desta forma, os mapas tiveram diversas funções ao longo do tempo e no espaço. A princípio como ficção, um meio de se pensar o mundo através dos mitos e crenças, com a observação do mundo, elaboração de instrumentos e vivências, com o desenvolvimento da capacidade de medir altitudes e coordenadas que foram se tornando cada vez mais objetivos (ACSELRAD; COLI, 2008). 0 primeiro registro é de 2300 a.C. na Babilônia com o objetivo de cobrança de impostos, na China do século II, com cunho militar e topográfico; no século XVII a.C., no Egito, mapas etnográficos representando povos com intuito cadastral, bem como buscando um planejamento para a agricultura, aproveitando as cheias dos rios; na Grécia e Império romano, com cunho político e de dominação de novos territórios, representando a si próprios no centro do mapa; no período medieval, os teólogos se apropriaram da ferramenta e representavam Jerusalém no centro do mapa, os árabes se preocuparam com a exatidão para a navegação e comércio; os Incas e Maias do século XII tinham mapas que representavam as terras do Império (ARANGO, 2007).

Mas foi com as grandes navegações que se fez cada vez mais necessário que os mapas fossem precisos e que descrevessem com exatidão a forma, tamanho e localização dos territórios "descobertos", o que "permitieran inferir y diagramar los potenciales recursos e intereses del poder colonial en su estabilización, integración y dominio, convirtieron a la cartografía en un saber estratégico y con un gran peso en la determinación de las relaciones multilaterales de poder" (ARANGO, 2007, p. 160).

No período pós-colonial os mapas passam a ter cunho de fortalecimento do Estado, delimitação de fronteiras entre outros (ACSELRAD, 2008), desta forma, começam a ser

[...] elaborados para facilitar e legitimar a conquista, definir o Estado como uma entidade espacial, assim como para construir nacionalismos pós-coloniais. Os cartógrafos ajudaram igualmente a produzir o "espaço social do desenvolvimento", por mapas que, neste contexto, possuem outras finalidades, tais como zoneamento e a gestão da utilização dos recursos naturais (ACSELRAD, 2008, p.9).

Quanto aos Zoneamentos, também são práticas geralmente oriundas do Estado, que por natureza são excludentes, socialmente esterilizantes e comumente elitistas e segregatórias (SOUZA, 2006). O que pode ser exemplificado com o estudo realizado por Mascarello e Santos (2015) com relação ao Superporto de Rio Grande (RS/Brasil). Na atualização do zoneamento da área portuária e retroportuária elaborado no ano de 2011 (Plano de Desenvolvimento e Zoneamento do Porto Organizado- PDZPO) desconsiderou-se a presença de duas das três comunidades existentes na área, uma delas com mais de 100 anos. Desta forma, invisibilizando-as e negando às mesmas o direito à moradia estabelecido na Constituição de 1988, bem como, a perpetuação de práticas tradicionais de uso e significação do território, uma vez que muitos moradores destas comunidades são pescadores artesanais.

Da mesma forma que o Estado atua espoliando as comunidades, utilizando os mapas como uma representação supostamente fidedigna do real, suprime informações relevantes ou adiciona 
inverdades quando lhe convêm. As empresas também agem assim, principalmente, nos processos de licenciamento ambiental, na venda de destinos turísticos, apresentação para investidores e outros. Afinal de contas, "o Estado e a Empresa, apesar de suas diferenças e às vezes de seus conflitos, convergem para a segregação" (LEFEBVRE, 2011, p.99).

O mapa é, portanto, um produto cultural do conhecimento/poder o qual monumentaliza e estabelece intencionalmente intervenções ou marcos da paisagem como referentes. Neste contexto, os mapas na sociedade atual foram estabelecidos como documentos essenciais na determinação dos direitos territoriais e de propriedade, de maneira que sua manipulação adquiriu um caráter estratégico, em que as omissões e silêncios intencionais permitiram resolver os projetos militares do Estado e os interesses comerciais para o estabelecimento de monopólios de mercado (ARANGO, 2007). Nesse sentido, Santos (2011) diz que

[...] diversos atores vêm se inserindo em disputas que articulam cartografias e relações de poder onde o que está em jogo pode ser, por exemplo, o controle do território, de propriedade, de comportamentos e relações sociais, de processos políticos ou, das próprias formas e instrumentos de representação. A valorização política e analítica da dimensão espacial de fenômenos, processos, objetos e atores transforma os instrumentos de representação espacial cada vez mais no centro de disputas de poder. Esta valorização do espaço é que faz com que a cartografia cada vez mais se cruze com jogos e disputas, ou, ela própria se torne objeto de disputa (SANTOS, 2011).

Essa centralização dos mapas como objeto de planejamento do espaço e de poder, em contrapartida, possibilitou uma disseminação social que

[...] tem sido entendida como portadora de múltiplos efeitos, desde a multiplicação democratizante das formas de interpretar o mundo, até o acirramento dos mecanismos autoritários de controle, próprios a uma "sociedade da vigilância". É neste contexto que, na série historicamente diversa das modalidades de mapas e de práticas de mapeamento, reunindo mapas administrativos, de desenvolvimento, de zoneamento, de penetração etc., os mapas ditos "participativos" vêm acrescentar um "surplus" de legitimidade na disputa cartográfica (ACSELRAD; COLI, 2008, p. 14).

Desta forma, o Estado e os empreendimentos capitalistas (empresas/corporações), hoje, são os dois maiores poderes na produção do espaço. Como outra forma de contar a história e planejar o espaço, no próximo subitem descreveremos um pouco sobre métodos participativos de se fazer cartografia e alguns exemplos de experiências realizadas no mundo e no Brasil.

\section{A CARTOGRAFIA SOCIAL COMO INSTRUMENTO DE LUTA}

A cartografia tradicional a partir do século XVII construiu um modelo científico padrão de conhecimento e cognição, considerando como objetivo do mapeamento a construção de um modelo real do terreno expresso por um modelo matemático estabelecendo assim a "verdade cartográfica" que 
poderia ser verificada de forma independente e objetiva (COLI, 2010). Algo que já vimos é que não passa de uma perspectiva da realidade.

Nesse sentido, Coli (2010) salienta que J.B. Harley "sugere uma nova epistemologia da história cartográfica fundamentada na teoria social e não no positivismo científico, indissociável das relações de poder, onde o papel da política, etnia, religião, classe social, etc. são essenciais para compreender o processo de construção de mapas". Assim, a cartografia vai muito além de uma figura que procura representar a realidade, mas como um texto cultural onde a retórica está sempre presente.

Uma vez que os poderes hegemônicos (Estado e Grandes Corporações) usam a cartografia, ferramentas de Geoprocessamento e Sistemas de Informações Geográficas - SIG com o objetivo de estabelecer verdades fixas e imutáveis sobre os territórios, porque não utilizar destes mesmos recursos para estabelecer, a partir do olhar das comunidades, suas verdades e contar suas próprias histórias? Criando, assim, mapas georreferenciados carregados de aspectos históricos, étnicos, culturais e de uso e significação do território.

Estes instrumentos podem, de alguma forma, munir estas comunidades, que são atingidas pelos Grandes Projetos de Desenvolvimento e pelos interesses econômicos, na manutenção da sua forma de vida e na garantia dos seus direitos. Instrumentalizando-as e empoderando-as para esta guerra de mapas, que muitas vezes caracterizam as audiências públicas, ações judiciais, conselhos de gestão do território e outros.

Neste viés diversos pesquisadores vêm contribuindo na construção deste conhecimento e no empoderamento por parte das comunidades atingidas através destas práticas, baseadas em três dimensões: o processo (o caminhar de construção do mapa), o objeto (o mapa em si) e o uso (a utilidade que esta comunidade vai dar ao mapa) (SANTOS, 2011).

A partir dos anos 90 diversas iniciativas surgiram em todo o mundo a fim de incluir populações locais nos processos de produção dos mapas, e contaram com a realização; apoio e financiamento de agências governamentais, ONGs, organizações indígenas, organismos de cooperação internacional, fundações privadas, universidades, entre outros. E ganha diversas terminologias, tais como: mapeamentos participativos, mapeamentos comunitários e mapeamentos colaborativos (ACSELRAD; COLI, 2008; ASSIS, 2010; HOFFMANN, 2010).

Um dos projetos pioneiros utilizando Sistema Participativo de Informações Geográficas - SPIG ocorreu no Canadá, com o Projeto de Uso e Ocupação de terras pelos Esquimós, tornando-se referência na área. Outras experiências foram observadas na África do Sul, no contexto da reconstituição da geografia histórica dos deslocamentos forçados no tempo do Apartheid, na definição de potenciais socioecológicos do solo, em políticas de acesso à terra e à água, assim como políticas de desenvolvimento. No Zimbabwe para obter informações sobre as mudanças no uso do solo e suas implicações na cobertura vegetal em torno dos rios e as enchentes decorrentes; em Moçambique numa 
luta cadastral para que recursos fossem tornados visíveis; nas Filipinas, para reconhecimento de domínios ancestrais; na Guatemala, foram feitos mapeamentos dos locais em que houve massacres perpetrados contra a população durante a guerra civil, buscando abrir espaço para a cultura dos direitos humanos no país; na República Dominicana, a fim de exaltar o papel da mulher na conservação da biodiversidade; em Chiapas, com o zoneamento camponês de áreas de fauna e flora, entre outros (ACSELRAD; COLI, 2008).

Todos estes exemplos remetem a lutas de minorias injustiçadas ambientalmente em obter reconhecimento e a ampliação de direitos. Essas abordagens participativas têm que procurar satisfazer aos anseios da maioria dos atores envolvidos, mas devem, prioritariamente, apoiar os atores menos favorecidos e articulados nesse processo (MCCALL, 2014), para que a construção desses mapas possa servir como base para construir as estratégias de atuação (HOFFMANN, 2010).

\subsection{Caso Brasileiro}

No Brasil vemos uma ampliação no uso da cartografia por parte de movimentos sociais articulados com Universidades e Centros de Pesquisa. Até o ano de 2008, em levantamento realizado pelo Projeto "Experiências em Cartografia Social", foram contabilizadas 118 experiências em que indígenas, quilombolas, pequenos produtores e extrativistas, foram envolvidos em mapeamentos dos territórios em que vivem e trabalham (ACSELRAD; COLI, 2008). Dentre eles, destacam-se os mapeamentos que precederam e deram origem às reservas extrativistas, no início da década de 90 o projeto que ficou conhecido como "A Guerra dos Mapas", "cujo pressuposto fundamental foi contribuir para a afirmação territorial de grupos sociais atingidos pelo Projeto Grande Carajás; e o Projeto Mamirauá, calcado em um envolvimento das comunidades da Reserva de Desenvolvimento Sustentável Mamirauá para fins de manejo e preservação da biodiversidade" (ACSELRAD; COLI, 2008, p. 26).

As reservas extrativistas surgiram e ganharam evidência no cenário nacional de unidades de conservação com a situação dos seringueiros na Amazônia, buscando a regularização fundiária de antigas áreas de seringais na Amazônia, tendo a figura emblemática de Chico Mendes a frente do processo. Para a adoção legal de uma reserva extrativista, o primeiro passo é que a comunidade solicite formalmente a reserva, para tanto, os seringueiros delimitaram um perímetro em torno a um conjunto de colocações, respeitando os limites dos antigos seringais (ACSELRAD; COLI, 2008; LITTLE, 2002).

Em reunião realizada em 8 de dezembro de 1985, os extratos de falas que abaixo reproduzimos, foram registrados:

Chico Mendes: Eu acho que, primeiramente, as áreas onde se criaram as reservas, seriam as áreas de conflito, onde os conflitos são evidentes e o pessoal está resistindo. (...) 
Osmarino Amâncio: Acho que o mapeamento tem que ser feito pelo conselho e os Assessores e as Reservas Extrativistas têm que ser onde têm seringueiro, onde tem seringa, onde tem castanha."(retirado de ACSELRAD; COLI, 2008, p. 29).

Esta fala retrata o reconhecimento e a associação destas comunidades de seringueiros com a terra em que vivem, trabalham e garantem sua subsistência. Elucida também que ninguém melhor que eles mesmos para dizer onde e porque é importante o mapeamento e a delimitação da reserva extrativista.

Desta forma, as Reservas extrativistas tornaram-se uma das primeiras iniciativas de automapeamento das comunidades tradicionais. Sendo esse um importante avanço por reconhecê-las legalmente como donas e gestoras do seu território.

A partir de 1990, tem início uma série de experiências de mapeamentos com comunidades que vivem na região de abrangência do Programa Grande Carajás (PGC). Procurou-se então identificar e sistematizar os diferentes tipos de conflitos na região: em torno das áreas das UC- Unidades de Conservação Ambiental, das RESEX- Reservas Extrativistas, das TI- Terras indígenas, em torno das áreas reservadas militares, das áreas concedidas, adquiridas e das pretendidas pela Companhia Vale do Rio Doce (CVRD), das reservas garimpeiras e das províncias auríferas, das áreas desapropriadas para projetos agrícolas e cooperativas, além dos conflitos situados em pontos variados nos territórios de grande predominância de babaçuais e castanhais, bem como, a resistência dos ocupantes das terras que eram ocupadas tradicionalmente há muitas gerações, conhecidas como terras de preto, de santo, da igreja e de índio (ACSELRAD; COLI, 2008, p.29-30).

Em 1993, realizou-se, na cidade de Marabá-PA, o Seminário Consulta Carajás: Desenvolvimento ou Destruição. Com a presença de militantes e assessores de entidades populares e confessionais e sindicatos dos trabalhadores, o qual resultou na publicação de mapas construídos com a participação das populações envolvidas e do livro "Carajás: a Guerra dos Mapas" (ALMEIDA, 1993 como citado em ACSELRAD; COLI, 2008). Nos anos de 2013-2014 realizou-se o "Seminário Internacional Carajás 30 anos resistências e mobilizações frente a projetos de desenvolvimento na Amazônia Oriental", o qual foi executado em quatro etapas preparatórias: nas cidades de Belém e Marabá, no Estado do Pará, Santa Inês e Imperatriz, no Maranhão, e que teve sua Etapa Final realizada na capital maranhense no mês de maio ${ }^{4}$.

Desta maneira, "o mapa produzido no contexto do Seminário-Consulta rompe com a ideologia do 'arquivo morto', própria da rotina das instituições oficiais, e busca divulgar informações essenciais a molde de um banco de dados dinâmico, 'vivo', que pode ir sendo complementado localmente por trabalhadores rurais, garimpeiros, pescadores, colonos e indígenas, bem como pelas entidades de apoio, locais ou confessionais, pelas cooperativas e pelos sindicatos. Esse mapa, ao contrário de uma realidade fixa ou de uma imagem congelada, se pretende em movimento, sendo redesenhado sucessivamente consoante o ponto de vista dos povos indígenas e dos seguimentos camponeses dispostos em situações críticas de conflitos ignoradas pelos planejadores oficiais. Sua configuração exprimiria sempre alterações na correlação de forças entre aqueles seguimentos sociais citados e os interesses que lhes são historicamente hostis, abrindo portas para incorporar uma recente 'ocupação', a

4 Mais informações sobre o evento pode ser conferida na página do mesmo, disponível em: http://www.seminariocarajas30anos.org/. 
homologação de uma área indígena ou mesmo sua auto-demarcação, uma desapropriação por interesse social, os registros de homicídios dolosos em conflitos agrários ou a fundação de mais uma cooperativa de pequenos produtores agrícolas e extrativistas" (ALMEIDA, 1993 como citado em ACSELRAD; COLI, 2008 p.31-32).

Essa nova forma de se pensar e se fazer os mapas permite um sentimento de pertencimento das comunidades para com estes produtos cartográficos. Faz com que se sintam representadas naquele desenho, vendo sua realidade exposta e divulgando em outros meios a situação em que se encontram, geralmente sofrendo pressão política, desapropriação e sendo espoliadas em seus territórios. A construção coletiva da representação de seus territórios e de suas histórias dá força a estas comunidades no embate político, não apenas pelo produto cartográfico, mas pelo processo que aumenta a coesão na comunidade, a auto-estima e revela de forma gráfica os vários sentimentos que muitas vezes ficam reprimidos.

Os projetos iniciados com a Guerra dos Mapas deram sustentação a outro projeto desenvolvido a partir de 2004, o Projeto Nova Cartografia Social dos Povos e Comunidades Tradicionais do BrasilPNCSA, financiado pela Fundação Ford.

O PNCSA surge com o objetivo de "mapear estes esforços mobilizatórios, descrevendo-os e georreferenciando-os, com base no que é relevante pelas próprias comunidades" onde buscam "analisar os processos diferenciados de territorialização" (ALMEIDA, 2013, p. 28). Torna-se hoje certamente o maior esforço de cartografia social empregado no Brasil. Leite Lopes (2013, p. 24) diz ser "testemunha da importância do PNCSA como formulador e produtor de pesquisas originais sobre a identidade social de grupos sociais na Amazônia e em diversas áreas do país", e ainda destaca que a "gama de publicações do projeto é impressionante, e de outros resultados do PNCSA se ouvirá falar mais no futuro".

O PNCSA acredita que o mapeamento social

[...] consiste num instrumento que fortalece a emergência de identidades coletivas e relativiza a ênfase na biodiversidade, no caso da Amazônia, colocando-a como atrelada à diversidade cultural e à mobilização destes povos e comunidades tradicionais em torno de seus direitos territoriais (ALMEIDA, 2013, p.34).

As publicações produzidas pelo PNCSA permitem "a leitura de como o conhecimento espacial produzido é o resultado de um encontro de conhecimentos" (VIANNA JR., 2013), e "tem ainda uma função pedagógica" (ALMEIDA, 2009, p. 31), por possibilitar o entendimento dos diferentes interesses presentes sobre um determinado território.

O projeto conta com diversas formas de divulgação e ampliação das lutas, seja através da internet (http://novacartografiasocial.com/) ou com a produção de boletins informativos e fascículos sobre as cartografias sociais construídas, os quais até dezembro de 2012 contava com 40 livros, 129 fascículos, cinco mapas-sínteses, cinco Boletins informativos, três cadernos de debates Nova Cartografia Social e 16 vídeos exibidos pela TV Futura e pelos programas ‘Globo Ecologia' e 'Globo 
Ciência' e pelo próprio PNCSA, totalizando entre livros e fascículos, mais de 200 mil exemplares (ALMEIDA, 2013).

Já o Projeto Marimauá ocorre na Confluência dos rios Solimões e Japurá, nas proximidades da cidade de Tefé no Estado do Amazonas. Iniciou-se em 1992 na Reserva de Desenvolvimento Sustentável Marimauá e buscou utilizar os mapeamentos participativos como subsídios na elaboração de planos de manejo florestal comunitário nesta Unidade de Conservação, tendo como pressuposto fundamental a conservação da biodiversidade. Em 1996 a Reserva de desenvolvimento SustentávelRDS foi criada no Estado do Amazonas e posteriormente incorporada ao Sistema Nacional de Unidades de Conservação- SNUC em 2000.

Dentre esses estudos, foram de grande importância as técnicas de mapeamento participativo para identificação dos usos tradicionais, e também para a identificação de potenciais conflitos entre assentamentos humanos, e conflitos entre os interesses da população e os resultados das pesquisas ambientais desenvolvidas. Este conjunto de conhecimentos gerou uma série de mapas de Mamirauá que, sobrepostos, permitiram a identificação de zonas de intenso uso e de grande importância para a proteção da biodiversidade. (QUEIROZ, 2005, p. 193).

Como produto das reuniões e negociações realizadas nas comunidades obtém-se o Mapa Oficial de Uso Sustentado dos Recursos Florestais do Setor, onde consta a demarcação das áreas de manejo florestal de cada comunidade e a área a ser manejada no primeiro ano de implantação (ACSELRAD; COLI, 2008).

Estas três experiências pioneiras e bastante distintas dão base a outros diversos trabalhos que vêm sendo desenvolvidos no Brasil, buscando instrumentalizar as comunidades locais frente a conflitos ambientais, bem como do acesso à terra, manutenção de práticas ancestrais, cogestão dos recursos naturais entre outras.

Podemos perceber em comum nestas três experiências apresentadas, o Estado como um dos atores (ou interlocutores), seja pela necessidade de demarcação das terras e/ou resolução de conflitos e injustiças ambientais.

Mas, se de um lado elas nos mostram que uma crítica à(s) cartografia(s) oficial(s) vem se fortalecendo, de outro elas nos chamam a atenção para um olhar sobre como o Estado vem reagindo neste debate sobre objetos, usos e processos de produção cartográfica. E o Estado se revela fundamentalmente uma complexa e múltipla 'arena', muito mais do que um ator (SANTOS, 2011, p. 47).

A resposta do Estado a estes mapeamentos é complexa, mas ela nos indica respostas/caminhos de que a cartografia vem se colocando como um instrumento de luta para grupos historicamente excluídos e invisibizados, e que instrumentalizados se colocam como resistências às forças hegemônicas na produção e organização do espaço. 


\subsection{SIG avanço ou retrocesso?}

A partir dos anos 2000, fortaleceu-se o uso dos SIGs nas metodologias participativas, alegando sua "autoridade/perícia legítima para fazer valer as reinvindicações sobre territórios e seus recursos por parte de populações locais" (ACSELRAD; COLI, 2008, p.18).

Sieber (2006, p. 491, tradução livre) destaca que são 3 razões principais para o interesse voltado para o SIG:

A primeira, é que a maior parte das informações utilizadas na formulação de políticas, seja referente à criminalidade, planejamento de uso do solo, saúde ambiental, conservação de habitat ou provisão de serviços sociais contém um componente espacial (por exemplo, endereço, código postal, longitude/latitude). Segunda, a ampliação do uso de informações espaciais para todas as partes interessadas leva presumidamente a uma melhor formulação de políticas. Terceira, (...), estas informaç̃̃es politicamente relacionadas podem ser analisadas e visualizadas espacialmente, e o produto resultante -maioria mapas- pode transmitir ideias de forma persuasiva e convencer as pessoas da importância destas ideias.

O autor ainda destaca o grande volume de dados espaciais gerados e o desenvolvimento de tecnologias cada vez mais acessíveis. Entretanto, não se pode pensar que apenas o uso da ferramenta tornará as experiências mais participativas, muitas vezes tem papel contrário afastando-se cada vez mais da população local, ficando cada vez mais a cargo do técnico.

A utilização e a capacidade de apropriação por parte de populações subalternas dos SIG e das tecnologias a elas associadas segundo seus próprios objetivos parece, entretanto, confrontar-se com formas mais complexas de relações de poder e dominação que envolvem interesses de determinados grupos, instituições, países e grandes corporações de software (COLI, 2010).

Softwares esses, predominantemente desenvolvidos nos Estados Unidos da América e com importantes projetos associados a este governo bem como a grandes corporações. Neste sentido

0 "trabalho manual" não se separa aqui do "trabalho intelectual", uma vez que ambos são considerados intelectuais, havendo índios, quilombolas e ribeirinhos que se tornam capacitados para utilizar GPS ou programas como ArcGIS e o fazem com competência técnica e em consonância com os interesses de seu povo ou comunidade de referência. A competência técnica aparece aqui associada ao capital militante, ampliando consideravelmente o espectro da produção de mapas e redefinindo profundamente o uso corrente de "participação", que não qualifica o tipo de comunidade em jogo nem tampouco o tipo de conhecimento que pode vir a produzir. Tem-se um aprimoramento do conhecimento das realidades localizadas possibilitado pela combinação entre a população científica e as disciplinas militantes. As comunidades tradicionais tornam-se, neste sentido, uma fonte de produção de informação cartográfica que poderão em um futuro próximo estar habilitadas a um monitoramento em tempo real de seus próprios territórios, ou melhor dizendo, de terras indígenas, das terras de quilombos, das áreas de babaçuais e das terras de ribeirinhos, bem como das terras de faxinais ou áreas de moradia e criatório comum, no Paraná, ou de comunidades de fundos de pasto, na Bahia, entre outras. Poderão fazê-lo em tempo real, mesmo considerando o aprendizado de interpretação das imagens de satélite e das dificuldades na região amazônica de se ter boas imagens, no período chuvoso, em virtude da presença constante de nuvens (ALMEIDA, 2013, p.32). 
Isto mostra a potencialidade das ferramentas quando utilizadas de forma bem intencionadas e quando não se dissocia a prática da teoria, tendo claro que os principais e mais amplamente utilizados softwares de SIG foram desenvolvidos pelo mercado e para o mercado e que mesmo as técnicas de metodologia participativa destes softwares baseiam-se no Banco Mundial, onde a ideia de participação está focada na comunidade como somatório do indivíduo e não como uma construção coletiva, existem hoje softwares independentes (como, por exemplo, o QGIS) desenvolvidos por pesquisadores engajados na causa que fomentam estas atividades. Desta forma, estas ferramentas podem ser utilizadas como um meio, desde que não se perca o senso crítico de como foram criadas, através de que meios e para que fins, bem como, "considerar a relevância que possuem os discursos e práticas acerca dos SIG elaborados e justificados por determinados atores com amplos recursos para interferir sobre processos desta natureza" (COLI, 2010, p.118).

\section{EXEMPLOS DE INSTRUMENTOS DE LUTAS PAUTADOS NO MAPEAMENTO DOS CONFLITOS}

Desde uma perspectiva e metodologia diferente dos mapeamentos participativos, mas com mesmo fim, de instrumentalizar e subsidiar as comunidades injustiçadas ambientalmente, alguns observatórios dos conflitos vêm trabalhando no sentido de mapear os conflitos ambientais e subsidiar as comunidades atingidas com base teórica e dados geoespacializados, como é o caso do Observatório dos Conflitos Ambientais de Minas Gerais e Observatório dos Conflitos Urbanos e Socioambientais do Extremo Sul do Brasil que descreveremos na sequência.

Observatório dos Conflitos Ambientais de Minas Gerais

A pesquisa que deu origem ao mapa de conflitos ambientais de Minas Gerais iniciou no ano de 2007, envolvendo uma parceria entre o Grupo de Estudos em Temáticas Ambientais (GESTA - UFMG), Núcleo de Investigações em Justiça Ambiental (NINJA - UFSJ) e o Núcleo Interdisciplinar de Investigação Socioambiental (NIISA - UNIMONTES), sendo lançado no ano de 2011 através do portal eletrônico - http://conflitosambientaismg.lcc.ufmg.br, sendo levantados 540 conflitos ambientais, que certamente não são a totalidade dos mesmos (ZHOURI; SAMORA, 2013; ZHOURI, 2014), foi posteriormente revisado (2012-2014) (ZHOURI, 2014). Como destacado por Zhouri (2014, p. 112)

[...] a partir de uma proposta qualitativa, centrada nas lutas dos diferentes sujeitos sociais para legitimar suas formas de ver, ser e fazer socioambientalmente constituídas, o mapa possibilita visualizar dinâmicas socioespaciais conflitivas para além de uma mera exposição de problemas e impactos ambientais em nossa sociedade.

Para a construção do mapa foi formada uma equipe interdisciplinar e interinstitucional, todas públicas e localizadas no território mineiro. Para conseguir dar conta de complexidade foram formadas duas frentes de trabalho: a primeira nos casos institucionalizados desde 2000 e a segunda nos casos não institucionalizados, realizada com oficinas com os atores nos territórios (ZHOURI, 
2014). Nessa segunda parte "buscou-se o diálogo com os sujeitos envolvidos em ações coletivas e estratégias de denúncia e mobilização para identificação e reconhecimento das resistências às condições desiguais de uso e de distribuição do meio ambiente" (ZHOURI, 2014, p. 114).

Por isso, é importante frisar que

[...] a construção de um mapa a partir do ponto de vista dos próprios atores mobilizados por dinâmicas e processos envolvendo danos e/ou riscos socioambientais e a defesa do território, da saúde e dos meios essenciais para sua reprodução socioambiental, procurava-se também refletir junto a esses mesmos sujeitos as possibilidades estratégicas de incremento da participação nas decisões das políticas ambientais do Estado (ZHOURI, 2014, p. 114).

Ou seja, entender a construção dos mapas (mapeamento) como um processo de empoderamento e emancipação ${ }^{5}$ dessas comunidades, um processo político.

Cabe ainda destacar que a experiência do mapa de Conflitos Ambientais de Minas Gerais traz ainda outras experiências importantes como o uso de novas tecnologias, como por exemplo, o uso das redes sociais (Facebook e Twitter).

Observatório dos Conflitos Urbanos e Socioambientais do Extremo Sul do Brasil

O Observatório dos Conflitos do Extremo Sul do Brasil surgiu em 2011 com uma proposta de mapear os conflitos urbanos e ambientais em onze municípios dessa região, tendo como inspiração o Observatório de Conflitos Urbanos da Cidade do Rio de Janeiro (ETTERN/IPPUR/UFRJ) (SANTOS; MACHADO, 2013; SANTOS et al., 2015).

Conforme destacam Santos et al. (2015, p. 19) o mapeamento consiste em:

[...] acompanhamento dos periódicos (jornais) diários e semanais, locais, regionais e estaduais; leitura para triagem das notícias com conflitos, problemas ou temas a serem úteis às pesquisas em desenvolvimento; leitura de triagem; recorte; separação por categoria; digitalização; alimentação do banco de dados digital; arquivamento.

Sendo visto como uma forma de "expor e problematizar os conflitos ambientais e urbanos em nossa sociedade", podendo a partir deles problematizar "os diferentes problemas existentes e sobre a injustiça e a desigualdade presentes na região do Extremo Sul do Brasil", pautando assim uma outra forma de se fazer, uma outra forma de planejar (SANTOS et al., 2015, p. 22).

0 mapeamento de conflitos encontra-se disponível no site do Observatório ${ }^{6}$, o qual foi construído através de convênio entre a Universidade Federal do Rio de Janeiro- UFRJ e a Universidade Federal do Rio Grande - FURG. É importante frisar que o site torna-se "uma importante ferramenta de publicização dos conflitos socioambientais da região do Extremo Sul do Brasil, por reunir em um só espaço as notícias sobre os mesmos" (SANTOS et al., 2015, p. 20). Um próximo passo indicado pela equipe do Observatório é a realização de oficinas de cartografia social com as comunidades e coletivos que apareceram nesse primeiro mapeamento.

\footnotetext{
5 Entendendo emancipação como "uma forma de se sair de uma situação de minoria" como destacado por Jaques Rancière (2012).

${ }^{6}$ http://www.observaconflitos.ippur.ufrj.br/extremossul/ajax/indexajax2.asp.
} 
Hoje, o Observatório acompanha o processo de resistência à implementação do projeto de Mineração, no município de São José do Norte/RS, da empresa Rio Grande Mineração. Procurando fazer o assessoramento técnico do Movimento Contra Mineração em São José do Norte, no que se refere às demandas no processo de luta e resistência. Com uma proposta de construção de uma cartografia para especializar toda a riqueza e valor do território, com objetivo de contrapor o discurso propalado pela empresa mineradora de "terra arrasada".

O Observatório também utiliza as redes sociais (Facebook) como uma ferramenta de interação com a população e os grupos sociais.

\section{CONSIDERAÇÕES FINAIS}

Concluímos que os mapas, por definição, são instrumentos de delimitação territorial e controle social, produzidos pelos militares, Estado e mais recentemente pela Iniciativa Privada (Corporações), mas que também podem ser fruto das inquietações sociais, refletindo as demandas de uma determinada comunidade através dos mapeamentos participativos.

Desta forma, os mapeamentos participativos são um instrumento de alto valor para empoderar as comunidades tradicionais (indígenas, quilombolas, ribeirinhos, extrativistas, entre outros) na luta pelos seus territórios, bem como, na perpetuação das suas práticas ancestrais, desde que sejam feitos de forma realmente participativa, que os técnicos sirvam de consultores das comunidades, buscando promover os debates.

E, por este alto valor, é um instrumento em disputa, que provoca tensões e apropriações por dialogar com conhecimentos e saberes tradicionais e com conhecimentos técnicos, sugerindo assim, o aprofundamento do olhar para estas cartografias, e mais ainda, para seus cartógrafos.

Há, ainda, muito que aprimorar no que se refere à metodologia dos mapeamentos, porém acreditamos que os exemplos mencionados estão no caminho certo, por buscarem empoderar as comunidades, munindo-as com instrumentos de luta produzidos por elas visando confrontar o poder hegemônico.

Uma das debilidades desta prática ainda está no texto final e publicações que decorrem destes mapeamentos, uma vez que os atores envolvidos não encontram tempo e incentivo para escrever sobre suas experiências, ou ainda são relutantes em tornar público essas informações devido às sensibilidades políticas, legais, econômicas e culturais envolvidas. A maioria dos textos disponíveis é produzida por acadêmicos, e mais recentemente, por técnicos em SIG, o que faz com que as perspectivas destes povos locais sejam representadas de forma incompleta.

Desta forma, consideramos importante que novas experiências de cartografia continuem surgindo a fim de denunciar as injustiças e desigualdades ambientais. E dessa maneira, chegar-se ao 
ponto em que as próprias comunidades tenham autonomia de saber quando, onde e por que usar estes instrumentos, de forma que os técnicos e pesquisadores sirvam apenas de consultores/assessores possibilitando uma cartografia social crítica e emancipatória. Para fomentar as necessidades da comunidade, feito pela comunidade e para a comunidade.

\section{REFERÊNCIAS}

ACSELRAD, H. As práticas espaciais e o campo dos conflitos ambientais. In: ACSELRAD, H. (Org.). Conflitos Ambientais no Brasil. Rio de Janeiro: Relume-Dumará: Fundação Heinrich Böll. 2004. p. 13-34.

- Apresentação. In: Acselrad, H. (org). Cartografias Sociais e Território. Rio de Janeiro: UFRJ, IPPUR. 2008.

(org). Cartografias Sociais e Território. Rio de Janeiro: UFRJ, IPPUR. 2008.

(org). Cartografia Social e dinâmicas territoriais: marcos para o debate. Rio de Janeiro: UFRJ, IPPUR. 2010.

(org). Cartografia Social, terra e território. Rio de Janeiro: UFRJ, IPPUR. 2013.

ACSELRAD, H., COLI, L. R. Disputas Cartográficas e disputas territoriais. In: ACSELRAD, Henri (org). Cartografias Sociais e Território. Rio de Janeiro: UFRJ, IPPUR. 2008.

ACSELRAD, H., MELLO, C., BEZERRA, G.N. O que é justiça Ambiental? Rio de Janeiro: Garamond. 2009.

ALMEIDA, A. W. B. d. Mapeando Vidas: grupos Sociais da Amazônia aprendem cartografia, retratam suas identidades e pressionam por políticas públicas. Revista de História da Biblioteca Nacional. maio. 2009. p. 28 -31.

Mapas Situacionais e categorias de identidade na Amazônia. In: ALMEIDA, A. W. B.; FARIA JÚNIOR, E. de A. (Orgs.). Povos e comunidade nova cartografia social. Manaus. 2013. p. 28 - 34.

. Mapeando Vidas: grupos Sociais da Amazônia aprendem cartografia, retratam suas identidades e pressionam por políticas públicas. Revista de História da Biblioteca Nacional. maio. 2009. p. 28 $-31$.

ALMEIDA, A. W. B.; FARIA JÚNIOR, E. de A. (Orgs.). Povos e comunidade - nova cartografia social. Manaus. 2013.

ARANGO, V. M. El mapa de lo invisible. Silencios y gramática del poder en la cartografía. universitas humanística, n.63, 2007. p. 155-179.

ASSIS, W. F. T. Conflitos Territoriais e disputas cartográficas: tramas sociopolíticas no ordenamento territorial no Oeste do Pará. In: ACSELRAD, H. (org). Cartografia Social $e$ dinâmicas territoriais: marcos para o debate. Rio de Janeiro: UFRJ, IPPUR. 2010. p. 163 - 193.

COLI, L. R. Sistemas de Informação Geográfica e iniciativas participativas de mapeamentos: estratégias, ambiguidades e assimetrias. In: Acselrad, H. (org.). Cartografia social e dinâmicas territoriais: marcos para o debate. Rio de Janeiro: UFRJ, IPPUR. 2010. p.93-122.

DAOU, A. M. Um espaço social fora do mapa: as lutas que as águas ensejam e o território como disputa. In: ACSELRAD, H. (org.). Cartografia Social, terra e território. Rio de Janeiro: UFRJ, IPPUR. 2013. p. 81-118.

HARLEY, J.B. Desconstructing the map. Cartographica, v.26, n.2, 1989. p. 1-20.

HOFFMANN, M. B. Mapeamentos participativos e atores transnacionais: a formação de identidades políticas para além do Estado e dos grupos étnicos. In: Acselrad, H. Cartografia social $e$ dinâmicas territoriais: marcos para o debate. Rio de Janeiro: UFRJ, IPPUR. 2010. p. 47-80.

LACOSTE, Y. A Geografia isso serve, em primeiro lugar, para fazer a guerra (Tradução Maria Cecília França). Campinas, SP: Papirus, 1988.

LEFEBVRE, Henri. Direito à cidade (trad. Eduardo Farias). 5 ed. 3. reimp. São Paulo: Centauro. 2011. $141 \mathrm{p}$.

LEITE LOPES, J. S. A Nova Cartografia e os movimentos sociais. In: ALMEIDA, A. W. B.; FARIA JÚNIOR, E. de A. (Orgs.). Povos $e$ comunidade - nova cartografia social. Manaus. 2013. p. 24.

LÉVY, J. Uma virada cartográfica? In: ACSELRAD, H. Cartografias Sociais e Território. Rio de Janeiro: UFRJ, IPPUR. 2008. p. 153-167.

LITTLE, P. E. Territórios Sociais e Povos Tradicionais no Brasil: Por uma Antropologia de territorialidade. 2002.

MCCALL, M. K. Mapping territories, land resources and rights: communities deploying participatory mapping/PGIS in Latin America. Revista do Departamento de Geografia - USP, Volume Especial Cartogeo. 2014. p. 94-122.

MASCARELLO, M. de A., SANTOS, C. F. Rio Grande (RS): entre a expansão portuária a invisibilidade social programada. In: Machado, C. R. S., Santos, C. F. \& Mascarello, M. de A. (Orgs). Conflitos 
Ambientais e Urbanos: casos do extremo sul do Brasil. Porto Alegre: Evangraf. 2015.

QUEIROZ, H. L. A Reserva de Desenvolvimento Sustentável Mamirauá. Estudos Avançados (19):54. 2005. p. 183-203.

RANCIÈRE, J. O espectador emancipado. São Paulo: Editora WMF Martins Fontes. 2012.128p.

SANTOS, C. F., LEMOS, C. O., OLIVEIRA, J., MACHADO, C. R. S. Observatório dos Conflitos do Extremo Sul do Brasil - debate sobre a zona de sacrifício e os conflitos ambientais e urbanos. In: MACHADO, C. R. S., SANTOS, C. F., MASCARELLO, M. de A. (Orgs). Conflitos Ambientais e Urbanos: casos do extremo sul do Brasil. Porto Alegre: Evangraf. 2015.

SANTOS, C. F. \& MACHADO, C. R. S. Extremo Sul do Brasil - uma grande "zona de sacrifício" ou "paraíso de poluição". In: Machado, C. R. S.; Santos, C. F., Araújo, C. F., \& Passos, W. V. (Orgs). Conflitos Ambientais e Urbanos: debates, lutas e desafios. Porto Alegre: Evangraf. 2013. p. 181204.

SANTOS, R. E. Cartografias e lutas sociais: notas sobre uma relação que se fortalece. In: SILVA, C. A., RIBEIRO A. C. T., CAMPOS, A., RESENDE, A. [et al.] (Orgs). Cartografia da ação e movimentos da sociedade: desafios das experiências urbanas. Rio de Janeiro: Lamparina: Faperj: Capes. 2011. p $41-42$.

SIEBER, R. Public Participation Geographic Information Systems: A Literature Review and
Framework. Annals of the Association of American Geographers, 96(3), 2006. p. 491-507.

SOUZA, M.L. Mudar a cidade: uma introdução crítica ao Planejamento e à Gestão Urbanos. 4 ed. Rio de Janeiro: Bertrand Brasil. 2006. 560 p.

VIANNA JR., A. Mais que um catálogo. In: ALMEIDA, A. W. B.; FARIA JÚNIOR, E. A. (Orgs.). Povos $e$ comunidade - nova cartografia social. Manaus. 2013. p. 95 - 96.

ZHOURI, A. (2014). Mapeando desigualdades ambientais: mineração e desregulação ambiental. In: ZHOURI, A.; VALÊNCIO, N. Formas de matar, de morrer $e$ de resistir: limites da resolução negociada de conflitos ambientais e garantia dos direitos humanos e difusos. Belo Horizonte: Editora UFMG. p. 111 - 142.

ZHOURI, A.; OLIVEIRA, R. Quando o lugar resiste ao espaço: colonialidade, modernidade e processos de territorialização. In: ZHOURI, A.; LASCHEFSKI, K. (orgs.). Desenvolvimento e Conflitos Ambientais. Belo Horizonte: Editora da UFMG. 2010. p. 439-462.

ZHOURI, A.; SAMORA, V. Conflitos Ambientais e a experiência de mapeamento em Minas Gerais. In: MACHADO, C. R. S., SANTOS, C. F., Araújo, C. F., PASSOS, W. V. (Orgs). Conflitos Ambientais $e$ Urbanos: debates, lutas e desafios. Porto Alegre: Evangraf. 2013. p. 161-180. 